\title{
A Vigilância nos Ambientes e Processos de Trabalho em Palmas - Tocantins: Diagnóstico Situacional e Contribuições ao setor.
}

\section{The Surveillance in the Environments and Work Processes in Palmas - Tocantins: Situational Diagnosis and Contributions to the sector.}

\section{La vigilar el medio ambiente y procesos de trabajo en Palmas - Tocantins: Diagnóstico situacional $\mathrm{y}$ contribuciones a la industria.}

RESUMO: Este estudo teve como objetivo contribuir com a reestruturação do processo de trabalho do Núcleo de Vigilância nos Ambientes e Processos de Trabalho da Vigilância em Saúde do Trabalhador do município de Palmas - Tocantins, descrevendo o mesmo, identificando suas fragilidades e buscando soluções, sendo este Núcleo, portanto, o universo da pesquisa. Trata-se de um estudo descritivo tipo intervenção, constituído por quatro fases. A fase I contextualizou historicamente a Saúde do Trabalhador no município de Palmas - TO; A fase II descreveu o atual processo de trabalho da equipe de Vigilância em Ambientes e Processos de Trabalho; Na fase III foram identificadas as necessidades da equipe quanto às melhorias necessárias; A fase IV foi destinada à construção dos fluxos e instrumentos necessários para a estruturação do setor no planejamento e execução de suas ações. A história da Saúde do Trabalhador no município iniciouse em 2004, a partir da habilitação do CEREST Regional de Palmas, perpassando por várias fases até a habilitação do Núcleo de Vigilância em Saúde do Trabalhador. Foram identificadas ausência de legislações municipais para a saúde do trabalhador, da Comissão Intersetorial de Saúde do

1 Fisioterapeuta Residente em Saúde Coletiva pela Fundação Escola de Saúde Pública de Palmas - TO, Brasil. Email: freitas-renata@hotmail.com

2 Mestre em Saúde Pública, Preceptora da Residência Multiprofissional pela Fundação Escola de Saúde Pública de Palmas - TO. E-mail: betaniacangussu@gmail.com 
Trabalhador junto ao Conselho Municipal de Saúde e de recurso federal. Também se percebeu a informalidade nas solicitações de demandas e respostas entre os setores da Vigilância em Saúde do Trabalhador e um fluxo não estruturado na rotina do serviço. Desta forma, o trabalho trouxe contribuições de intervenção nesta realidade, de maneira participativa e democrática.

Palavras-chaves: Vigilância, Saúde do Trabalhador; Processos de Trabalho.

ABSTRACT: This study aimed to contribute to the restructuring of the work process of the Nucleus of Surveillance in the Environments and Work Processes of the Occupational Health Surveillance of the municipality of Palmas - Tocantins, describing the same, identifying its fragilities and seeking solutions, this Nucleus Therefore, the universe of research. It is a descriptive, intervention-type study, consisting of four phases. Phase I has historically contextualized the Worker 's Health in the municipality of Palmas - TO; Phase II described the current work process of the Surveillance Team in Environments and Work Processes; In phase III, the team's needs were identified for the necessary improvements; Phase $I V$ was devoted to the construction of the necessary flows and instruments for structuring the sector in the planning and execution of its actions. The history of Workers' Health in the municipality began in 2004, starting with the CEREST Regional de Palmas accreditation, going through several phases until the Enabling Nucleus of Worker's Health Surveillance. Difficulties were identified in the absence of municipal legislation for workers' health, the Inter-Sectoral Worker's Health Committee with the Municipal Health Council and federal appeal. Informality was also perceived in the requests for demands and responses between the sectors of Occupational Health Surveillance and an unstructured flow in the routine of the service. In this way, the work brought contributions of intervention in this reality, in a participatory and democratic way.

Key words: Surveiillance, Occupational Health, Work Processes.

RESUMÉN: Este estudio tuvo como objetivo contribuir a la reestructuración de la Unidad de Vigilancia del proceso de trabajo en el medio ambiente y procesos de trabajo de Vigilancia de la Salud de la ciudad de Palmas Trabajador - Tocantins, que describe el mismo, identificando sus debilidades y la búsqueda de soluciones, y este núcleo Por lo tanto, el universo de investigación. Se trata de una intervención de tipo de estudio descriptivo que consta de cuatro fases. Fase I históricamente contextualizado trabajador de la salud en la ciudad de Las Palmas - A; Fase II describe los entornos de equipo de vigilancia del proceso de trabajo actual y los procesos de trabajo; En la fase III de las necesidades del equipo han sido identificadas como las mejoras necesarias; Fase IV fue para la construcción de los flujos y las herramientas necesarias para la estructura de la industria en la planificación y ejecución de sus acciones. La historia Salud en el Trabajo en la ciudad comenzó en el año 2004, de permitir Palmas CEREST regional, pasando por varias etapas para que el Centro de Vigilancia de la Salud en el Trabajo. El desarrollo de las dificultades de la falta de legislación municipal para el trabajador de la salud, Trabajador Comisión Intersectorial de Salud con el Consejo Municipal de Salud y fondos federales. También se dio cuenta de la informalidad en las solicitudes de demandas y respuestas entre los sectores de Vigilancia de la Salud Ocupacional y 
corriente no estructurado de la rutina de servicio. Por lo tanto, el trabajo llevado contribuciones de intervención en esta realidad, de una manera participativa y democrática.

Palabras chave: Vigilancia, Salud Ocupacional, Procesos de Trabajo.

\section{INTRODUÇÃO}

Compete ao Sistema Único de Saúde - SUS, realizar ações de promoção e proteção à saúde dos trabalhadores e trabalhadoras de maneira integral e universal, independentemente de sua localização, urbana ou rural, de sua forma de inserção no mercado de trabalho, formal ou informal, de seu vínculo empregatício, público ou privado, assalariados, autônomos, avulsos, temporários, cooperativados, aprendizes, estagiários, domésticos, aposentados ou desempregados 1, 2, 3, 4, 5 .

Para tanto, torna-se essencial o papel das equipes de Vigilância em Saúde do Trabalhador no SUS - VISAT na execução desta tarefa, de maneira contínua e sistemática, detectando, conhecendo, pesquisando e analisando os fatores determinantes e condicionantes dos agravos relacionados aos processos e ambientes de trabalho. O cumprimento destes itens permite a realização de um adequado planejamento, execução e avaliação das intervenções sobre os aspectos sociais, organizacionais e epidemiológicos ${ }^{3}$.

A VISAT integra a Vigilância em Saúde, acrescentando estratégias de produção de conhecimentos e mecanismos de intervenção sobre os processos de produção. Compõe um conjunto de práticas sanitárias centrada na relação da saúde com o ambiente e os processos de trabalho e nesta com a assistência, para a melhoria das condições de vida e saúde da população ${ }^{3}$.

Insere-se na VISAT a Vigilância de Ambientes e Processos de Trabalho - VAPT, sendo esta definida como o conjunto de ações que visam à prevenção e a redução dos riscos aos quais os trabalhadores estão expostos em decorrência de um ambiente, de uma atividade ou de um processo de trabalho, resultando na aplicação de medidas preventivas e/ou corretivas, englobando desde a investigação das formas de adoecimento do trabalhador até a solicitação de adequação para a prevenção de acidentes e agravos ${ }^{6}$.

A Vigilância de Ambientes e Processos de Trabalho - VAPT inicia-se a partir do conhecimento da realidade de saúde da população trabalhadora, considerando como objeto o processo, o trabalhador e o ambiente. As ações necessitam ser realizadas através de articulações intra e intersetoriais e planejadas a partir do estabelecimento de prioridades, com efeitos educativos e disciplinadores, utilizando as categorias base sindical, ramo produtivo, território e critério epidemiológico, individualmente ou de forma combinada ${ }^{3}$.

Para o desenvolvimento da ação, deve ser estabelecido o diagnóstico situacional dentro do princípio da pesquisa-intervenção, com avaliação permanentemente dos resultados pretendidos, sendo: fase preparatória, inspeção/fiscalização sanitária, análise dos processos, inquéritos, 
mapeamento de riscos, estudos epidemiológicos e acompanhamento do processo. Também devem ser verificadas as informações básicas acerca da mortalidade, morbidade, IBGE e relativas às atividades e aos processos produtivos ${ }^{3}$.

As atividades em questão não são desenvolvidas isoladamente, mas através de redes. O Ministério da Saúde, através da Rede Nacional de Atenção Integral à Saúde do Trabalhador - RENAST, implantou CEREST estaduais e regionais em estados e municípios brasileiros, além dos Núcleos Municipais de Saúde do Trabalhador, estes relacionam-se entre si e com os demais parceiros intra e intersetoriais ${ }^{4,7,8}$. As redes assumem diversos perfis na constituição do cenário de produção da saúde, podendo se organizar de diversas maneiras 9.

Desta forma, essa pesquisa surge a partir de solicitação da equipe que compõe o Núcleo de Vigilância nos Ambientes e Processos de Trabalho, inserido na Vigilância em Saúde do Trabalhador da Secretaria Municipal de Saúde de Palmas - Tocantins. Considera a necessidade de se rediscutir os fluxos do atual processo de trabalho deste setor, após a ocorrência de mudanças estruturais desencadeadas pela desabilitação do CEREST Regional de Palmas e criação do referido Núcleo a nível municipal, no ano de 2014.

Associam-se a este contexto, outras transformações na estrutura desta Secretaria, a partir do ano de 2016, quando foi estruturada a Rede de Atenção e Vigilância em Saúde - RAVS ${ }^{19}$.

Tem como objetivo contribuir com a reestruturação do processo de trabalho do Núcleo de Vigilância nos Ambientes e Processos de Trabalho da Vigilância em Saúde do Trabalhador do município de Palmas - Tocantins, descrevendo o mesmo, identificando suas fragilidades e buscando a construção coletiva das melhorias necessárias, desde o planejamento até a execução de suas ações.

\section{METODOLOGIA}

Trata-se de um estudo descritivo tipo intervenção, constituído por quatro fases. O universo pesquisado é o Núcleo de Vigilância nos Ambientes e Processos de Trabalho, inserido na Vigilância em Saúde do Trabalhador do município de Palmas - Tocantins. Foi realizado no período de agosto de 2016 a fevereiro de 2017, após seguir o fluxo da Secretaria Municipal de Saúde de Palmas para realização de pesquisa científica, através da aprovação do pré-projeto pela banca examinadora da FESP (Fundação Escola de Saúde Púbica) e anuência do Secretário, com posterior aprovação pelo Comitê de Ética em Pesquisa sob o protocolo nº 1.780 .713 em 19 de outubro de 2016.

A Fase I contextualizou historicamente a Saúde do Trabalhador no município de Palmas - TO, através de dados secundários, sendo, portarias ministeriais, trabalho de conclusão de curso que relata a história da construção da saúde do trabalhador na rede SUS do Tocantins, diagnóstico situacional realizado no ano de 2011 por residentes que atuaram no CEREST Regional de Palmas, resoluções do Conselho Municipal de Saúde - CMS e Comissão Intergestora Bipartite - CIB e plano de trabalho apresentado ao CMS e CIB para a Vigilância em Saúde do Trabalhador de Palmas 
no ano de 2014.

A Fase II descreveu o atual processo de trabalho da equipe de Vigilância em Ambientes e Processos de Trabalho, construindo seu diagnóstico situacional. Para tanto, foram analisados dados primários e secundários do local de pesquisa.

Os dados primários foram coletados através da observação participante com o intuito de examinar minuciosamente o objeto no seu todo e apreender a variedade de situações que ocorrem na rotina do ambiente laboral. Esta observação é utilizada como forma de coleta de dados empíricos na pesquisa qualitativa, onde o observador coloca-se na posição dos observados, devendo inserir-se no grupo a ser estudado como se fosse um deles, pois assim tem mais condições de compreender os hábitos, atitudes, interesses, relações pessoais e características do funcionamento daquele grupo, o que requer que o observador torne-se parte do universo investigado para entendimento do contexto das ações e apreensão dos aspectos simbólicos que o permeiam $^{10}$.

As pesquisadoras são residente e preceptora da Residência Multiprofissional em Saúde Coletiva, estando inseridas neste ambiente laboral, o que facilitou a referida observação.

1. Os dados secundários foram extraídos através de análise documental, de documentos relevantes para a pesquisa elaborados pelo setor, tais como relatórios técnicos e instrumentos utilizados para nortear as ações. Os documentos serviram de subsídios para a compreensão do contexto organizacional, no qual as atividades observadas estão inseridas.

2. Na Fase III, para a identificação das necessidades da equipe quanto à melhorias que venham a contribuir com a reestruturação dos fluxos desse processo de trabalho, foi utilizado como instrumento de coleta de dados o grupo focal, cuja essência consiste na interação entre os participantes e o pesquisador, que objetiva colher dados a partir da discussão focada em tópicos específicos e diretivos ${ }^{11}$. A coleta de dados através do grupo focal tem como uma de suas maiores riquezas basear-se na tendência humana de formar opiniões e atitudes na interação com outros indivíduos ${ }^{11}$.

3. A população estudada nesta fase foi composta por trabalhadores que atuam dentro da Vigilância em Saúde do Trabalhador do município de Palmas (Vigilância Epidemiológica de Campo da Saúde do Trabalhador e Vigilância de Ambientes e Processos de Trabalho) e que aceitaram participar do estudo e excluídos aqueles que não trabalham diretamente no local.

4. Vale ressaltar, que apesar da pesquisa ser específica ao Núcleo de Vigilância nos Ambientes e Processos de Trabalho, toda a equipe que atua na Vigilância em Saúde do Trabalhador foi convidada a participar, pois trabalham de maneira integrada, produzindo demandas reciprocamente. 
5. Todos os profissionais que aceitaram participar da pesquisa e que cumpriam os critérios de inclusão assinaram o Termo de Consentimento Livre e Esclarecido - TCLE. Participaram desta fase do estudo sete sujeitos, sendo duas psicólogas, uma odontóloga, duas assistentes sociais, uma fonoaudióloga e uma enfermeira.

6. A aplicação desta técnica ocorreu por meio de reuniões com o grupo de pessoas que integram a pesquisa, local onde foram estimuladas a expressarem seus pontos de vista sobre a atual estruturação deste processo de trabalho. Os pesquisadores fizeram o papel de mediadores, criando um ambiente propício para que diferentes percepções e pontos de vista viessem à tona e conduziram a discussão de modo que a reunião se mantivesse dentro dos tópicos de interesse, sem que houvesse geração de novos conceitos aos participantes, salientando as ideias relevantes e incentivando a discussão.

7. O grupo teve um encontro com duração de duas horas, foi conduzido na sala de trabalho da equipe, o que lhes assegurou anonimato e uso exclusivo para finalidades de pesquisa, em um horário que não prejudicou as atividades rotineiras dos participantes.

8. A análise dos resultados foi realizada através da técnica de análise do conteúdo, que ocorreu posteriormente a reunião, através do material de áudio gravado durante a realização do grupo focal, com a prévia autorização de todos os participantes. Depois de transcritas, as falas foram analisadas a partir de categorias construídas com os temas emergidos durante o grupo.

9. A análise de conteúdo é um conjunto de técnicas de análise das comunicações. Não se trata de um instrumento, mas de um leque de apetrechos, ou, com maior rigor, será um único instrumento, mas marcado por uma grande disparidade de formas e adaptável a um campo de aplicação muito vasto: as comunicações ${ }^{12}$. Pode ser aplicada na análise de textos escritos ou de qualquer comunicação oral, visual, gestual, procurando compreender o sentido da comunicação ${ }^{13}$.

A Fase IV foi destinada à construção dos fluxos e instrumentos necessários para a estruturação do setor no planejamento e execução de suas ações. Para tanto, a partir das necessidades identificadas na fase anterior por meio do grupo focal e análise documental, nessa fase foram elaborados os fluxos e instrumentos de trabalho como produtos das reflexões anteriores.

O mesmo ocorreu na forma de construção participativa com o Núcleo de Vigilância de Ambientes e Processos de Trabalho, tendo como base, outros produtos já existentes. A construção participativa, além de apresentar um produto rico, composto por múltiplos saberes, tem o efeito de formar uma opinião entre os trabalhadores em torno da realidade, uma consciência na equipe dos problemas enfrentados, como consequência da organização do processo de trabalho. $\mathrm{O}$ grupo produz uma organização do seu pensamento que lhe dá a real dimensão de como são produzidas 
as ações de saúde ${ }^{14}$.

Para que essa fase fosse concluída, ocorreu um novo encontro com os participantes envolvidos, momento em que foram apresentados e validados os dados obtidos, de modo a garantir que os mesmos contemplassem a realidade do serviço.

\section{RESULTADOS}

\section{I.Contextualização histórica da Saúde do Trabalhador no município de Palmas - TO}

A Rede Nacional de Atenção integral à Saúde do Trabalhador - RENAST foi a principal estratégia utilizada pelo Ministério da Saúde para a Vigilância em Saúde do Trabalhador no SUS. A mesma implantou Centros de Referência Estaduais, Regionais e Municipais nos estados e em vários municípios brasileiros ${ }^{4}$.

Nesse contexto, o município de Palmas - Tocantins esteve entre os primeiros municípios a implantar este serviço na sua região, sendo o Centro de Referência Regional em Saúde do Trabalhador de Palmas, habilitado em maio de 2004, através de pactuação entre os gestores federal, estadual e municipal ${ }^{15}$.

No ano de 2005, uma equipe recém-aprovada em concurso público foi lotada no referido Centro, contemplando a equipe mínima obrigatória, com equipamentos e mobiliários adequados para o serviço, tendo sido capacitados para o desenvolvimento de suas atribuições, inicialmente através de cursos de curta duração (nos anos de 2005 e 2006) e em anos posteriores através da realização de especialização e mestrado ${ }^{16}$.

Os anos que sucederam foram de aprendizados e descobertas. A partir da realização das conferências de saúde do trabalhador, na tentativa da compreensão do papel do CEREST, este serviço passou por períodos assistenciais, até definir-se que o mesmo não seria porta de entrada da rede SUS, mas que teria o papel de suporte técnico e científico, fato que se encontra mais claro nos dias atuais, principalmente a partir da publicação da Política Nacional de Saúde do Trabalhador e da Trabalhadora $5,7,16$.

Dessa forma, o serviço inseriu-se no organograma da Secretaria Municipal de Saúde de Palmas, na Diretoria de Vigilância em Saúde, Gerência do CEREST. No ano de 2010, com o intuito de atender a população de quinhentos mil habitantes exigidas pela portaria GM/MS n 2.728 de 11 de novembro de 2009, o CEREST Regional de Palmas ampliou sua abrangência de 14 para 75 municípios do estado, muitos destes, distantes da capital, mantendo para isso, o mesmo quantitativo de pessoal e processo de trabalho estabelecido, através dos núcleos de projetos e pesquisas, vigilância em ambientes e processos de trabalho e informação ${ }^{8,17}$.

Já no ano de 2014, o então gestor municipal questionou a existência do serviço a nível regional, 
para mais da metade dos municípios do estado. Argumentou sobre a impossibilidade de se fazer um serviço de qualidade na capital levando em consideração o território de abrangência e quantitativo limitado de pessoal, lembrando ainda que a política de saúde do trabalhador é transversal, necessitando perpassar por várias áreas.

Como a portaria ministerial ${ }^{8}$ exigia uma população mínima de 500 mil habitantes para habilitação de um CEREST municipal, a solução apresentada pelo gestor foi a desabilitação do serviço e criação de um Núcleo de Vigilância em Saúde do Trabalhador Municipal, com manutenção da equipe já capacitada para atuação na área. Esta proposta foi apresentada e aprovada no Conselho Municipal de Saúde e Comissão Intergestora Bipartite ${ }^{18}$.

A nova proposta contemplou a organização do serviço de Saúde do Trabalhador municipal em seis territórios e suas respectivas equipes, para apoio matricial e educação permanente em todos os níveis de atenção da rede SUS, além das ações de Vigilância nos Ambientes e Processos de Trabalho e foi seguida na íntegra durante os anos de 2014 e 2015, em contínua implementação. No ano de 2016 o mesmo sofreu pequenas adaptações, em virtude de mudanças na estrutura organizacional da Secretaria Municipal de Saúde ${ }^{19}$, fato que não impediu a continuidade das ações.

A desabilitação favoreceu a intensificação das atividades a nível municipal, tais como a análise do perfil produtivo e situação de saúde dos trabalhadores nos territórios do município, a oferta de retaguarda técnica especializada às equipes e planejamento e execução de ações conjuntas. Foram iniciadas a partir da Atenção Primária à Saúde, considerando o papel da mesma enquanto coordenadora do cuidado e ordenadora da rede $\mathrm{SUS}^{20}$.

Apesar disso, alguns percalços foram identificados durante a trajetória do serviço após sua desabilitação a nível regional, fatores esses que fragilizam ou dificultam a atuação da equipe em vários momentos. Os mesmos são perceptíveis nas falas dos atores envolvidos neste processo e serão apresentados nas demais fases deste estudo.

\section{Diagnóstico situacional do atual processo de trabalho da equipe de Vigilância em Ambientes e Processos de Trabalho do município de Palmas - TO:}

A Secretaria Municipal de Saúde de Palmas instituiu em junho de 2016, a Rede de Atenção e Vigilância em Saúde - RAVS, como forma de organização do sistema municipal de saúde e buscando garantir a integralidade do cuidado. Nesta, a Vigilância em Saúde do Trabalhador permanece inserida na Vigilância em Saúde. A RAVS organiza o município em oito divisões territoriais, sendo: Território de Saúde Canela, Apinajé, Xambioá, Krahô, Karajá, Javaé, Xerente e Pankararú ${ }^{19}$.

A Vigilância em Saúde do Trabalhador está subdividida em dois setores, que atuam em conjunto, sendo a Vigilância Epidemiológica de Campo da Saúde do Trabalhador e a Vigilância de Ambientes e Processos de Trabalho - VAPT, objeto de estudo desta pesquisa.

Tempus, actas de saúde colet, Brasília, 11(2), 199-217, jan, 2018.

ISSN 1982-8829 
O atual processo de trabalho do setor de Vigilância nos Ambientes e Processos de Trabalho se propõe a desenvolver ações geradoras de intervenção e redução dos riscos à saúde dos trabalhadores relacionados a um ambiente, a uma atividade ou a um processo de trabalho, em parceria com órgãos intra e intersetoriais, conforme preconizam as legislações ministeriais ${ }^{3}$.

Para tanto, conta atualmente com uma equipe de apenas dois técnicos efetivos e um residente, número reduzido se comparado há tempos anteriores, que possuía de quatro a cinco profissionais. O fato ocorreu porque recentemente o serviço sofreu a perda de três trabalhadores, que por necessidade da gestão, foram destinados a outras atividades da secretaria.

As demandas do serviço são organizadas seguindo os critérios territoriais, epidemiológicos, de atividade produtiva e denúncias sindicais e de trabalhadores, não sendo excludentes entre si. Para tanto, a equipe tem gradativamente realizado o levantamento das atividades produtivas do município (formais e informais), e distribuído às mesmas através dos territórios de saúde organizado pela RAVS, mapeando assim, o município em questão. Como o território vivo da cidade é dinâmico, esta ação ocorre continuamente.

Essas informações servem de subsídio para o planejamento e execução das ações. No ano de 2016, a equipe realizou em conjunto com os parceiros intra e intersetoriais (CEREST Estadual, Vigilância em Saúde Ambiental Estadual e Municipal e sindicatos da categoria) a vigilância por atividade produtiva em todos os postos de combustíveis da cidade, e consta no planejamento para o ano de 2017, o desenvolvimento dessas ações com as indústrias de mármores e granitos.

As ações de vigilância nos ambientes e processos de trabalho desencadeadas pelo critério epidemiológico ocorrem a partir da análise e envio dos dados das fichas de notificação pela vigilância epidemiológica de campo da saúde do trabalhador para este setor, podendo se referir a óbitos, acidentes de trabalho graves ou adoecimentos relacionados ao trabalho, cumprindo os requisitos para a inspeção in loco.

As denúncias de trabalhadores e sindicatos são recebidas através de ofícios ou pela ouvidoria da secretaria de saúde municipal, podendo o denunciante se manifestar ou manter o anonimato.

Além dessas demandas, outros parceiros intra e intersetoriais também costumam solicitar via ofício ou memorando a realização de inspeções para averiguação das condições de trabalho e saúde dos trabalhadores de estabelecimentos comerciais e industriais, sendo eles: Vigilância Sanitária Municipal, CEREST Estadual, Ministério Público, Ministério Público do Trabalho, dentre outros.

Os sindicatos são convidados a participar das inspeções in loco e grande parte deles costuma acompanhar a ação, desde seu planejamento até a execução. Toda ação gera um termo de visita, se tudo estiver em conformidade com a legislação, ou um termo de notificação, caso haja alguma irregularidade. 
Após expedido o termo de notificação, a empresa tem o prazo de trinta dias para as adequações, que pode ser prorrogado por mais trinta dias, a pedido da empresa. Finalizado o prazo, a equipe retorna ao local que ocorreu a vigilância para averiguação do cumprimento das inconformidades. Caso as mesmas não tenham sido sanadas, um relatório da situação identificada é encaminhado para o Ministério Público do Trabalho, via ofício.

\section{Necessidades da equipe para melhor estruturação dos fluxos do processo de trabalho:}

A participação dos técnicos no grupo focal se deu de forma bastante construtiva, os participantes se mostraram solícitos, empenhados em auxiliar no levantamento de questões que apresentavam falhas, bem como levantaram hipóteses e deram sugestões de como melhorar alguns pontos de fragilidade identificada, sendo elas:

a) Ausência de legislação municipal e do poder de polícia administrativa para a Vigilância em Saúde do Trabalhador:

[...] O que nós temos são as legislações nacionais, a nível municipal o que nós tínhamos era a portaria de habilitação do CEREST, depois que foi desabilitado nós não temos mais, a Vigilância Sanitária e a Ambiental tem leis municipais, nós não temos. Isso dificulta a organização do nosso trabalho e o andamento das ações.

[...]Então, nós sabemos que o ideal seria que em todas as ações a vigilância sanitária pudesse estar presente, mas na prática do serviço existe a dificuldade de agenda, eles tem a programação anual deles, para acrescentar as demandas não programadas ou programadas que requer um período de tempo maior, fica complicado. Além disso, nem todos os locais inspecionados são de competência da vigilância sanitária. Então várias vezes precisamos ir sem eles.

[...] A falta do poder de polícia já nos causou vários problemas, como sermos impedidos de entrar em estabelecimentos, sermos barrados, isso amarra nosso serviço.

Como a equipe desenvolve ações de campo, de inspeção nos estabelecimentos comerciais e industriais, necessita a todo momento se identificar para adentrar a estes locais, inclusive com poder de polícia administrativa quando necessário. O mesmo seria dispensável se sempre fosse possível contar com a participação da Vigilância Sanitária, mas muitas vezes isso não ocorre. Dessa forma, a falta do poder de polícia tem fragilizado, dificultado e prejudicado o desenvolvimento de várias atividades de vigilância nos ambientes e processos de trabalho.

b) Ausência da Comissão Intersetorial de Saúde do Trabalhador - CIST no Conselho Municipal de Saúde - CMS:

[...] A CIST municipal já existiu, mas há tempos não atua mais, isso é muito ruim, porque o controle 
social é que dá vida ao SUS, sentimos muita falta de uma CIST atuante no município.

Outro fator que tem fragilizado as ações de Vigilância nos Ambientes e Processos de Trabalho é a ausência da CIST Municipal no CMS, visto que esta comissão contribui com a Política Nacional de Saúde do Trabalhador e da Trabalhadora na articulação intersetorial necessária para o acompanhamento das ações em Saúde do Trabalhador, de políticas e programas de interesse para a saúde.

c) Ausência de recurso federal para o desenvolvimento das ações:

[...]A falta do recurso faz falta, nós compreendemos o argumento do gestor para atuar a nível municipal, mas é muito difícil planejar ações sem recurso, acredito que o ministério deveria disponibilizar algum recurso para os núcleos de saúde do trabalhador também, as outras áreas recebem, porque nós não?

Esta é uma fala consensuada entre o grupo, que tem sentido a dificuldade de planejar e executar ações sem nenhuma contrapartida nacional. Sabendo da dificuldade de se desenvolver uma política que busca a proteção social do trabalhador frente ao mercado capitalista e a grandes interesses comerciais, a falta do investimento federal compromete ainda mais a implementação efetiva da Vigilância em Saúde do Trabalhador no SUS.

d) Informalidade nas solicitações de demandas e respostas das mesmas entre os setores da Vigilância em Saúde do Trabalhador e serviços parceiros:

[...] a gente foi em uma unidade de saúde e os trabalhadores reclamaram a respeito dos protetores que eles recebiam, então nós levamos essa informação pra VAPT, para que eles pudessem fazer uma avaliação ou uma investigação para a verificação desse produto e nunca deu em nada, não tivemos resposta.

[...] Essas informações não podem ser trazidas verbalmente, precisa ser seguido o fluxo de denúncia, através da ouvidoria, notificação ou um ofício.

[...] não veio para a instituição VISAT, veio para uma técnica através do e-mail pessoal dela, é muito informal, não dá pra ser assim, tem que ter os fluxos certos da demanda [...]

Observa-se que apesar de existir um fluxo o mesmo não se encontra estruturado na rotina do serviço. As condições relatadas prejudicam a eficácia do trabalho desenvolvido, tornando o ambiente confuso e as relações fragilizadas. A fim de solucionar esses impasses, os técnicos propuseram algumas sugestões de melhorias:

[...] precisaria ver como essa solicitação pode ser feita do núcleo de epidemiologia para o VAPT, se precisaria de um formulário especifico ou cópia da notificação por exemplo [...]

[...] acho que seria um formulário mesmo, foi lá na unidade, tem determinada ação, vou encaminhar 
para a VAPT, preenche o formulário com todos os dados que necessita pra ação e pega um recebido [...] um fluxo de resposta de ida e vinda, esse formulário já tem que ter um campo pra colocar o tempo de resposta $[\ldots]$

[...] seria interessante estabelecer um prazo para resposta do pedido, porque se não você fica sem um feedback [...] nesse formulário mesmo que for criado coloca a data pra resposta, 15 dias, 30 dias, e o técnico que levar já pega um recebido e lá já tem que constar o prazo de devolutiva.

[...] quando o técnico recebe a denúncia informal, ele deve orientar a pessoa a oficializar a demanda, a ligar na ouvidoria [...] ou então a instituição sindicato mandar um oficio pra gente.

A proposta apresentada pela equipe foi a de que ocorresse a elaboração de um formulário interno para referência e contra-referência entre os núcleos da Vigilância em Saúde do Trabalhador. O mesmo deveria conter o motivo da solicitação da ação, bem como a estipulação de um prazo para a realização da mesma e encaminhamento de parecer com resposta ao solicitante.

Além disso, também foi apontado como solução para informalidade das solicitações externas de ação, o compartilhamento do fluxo de entrada dessas demandas, que devem vir acompanhadas de um documento do solicitante (ofícios, memorandos, formulários internos) dependendo do setor gerador da demanda. O mesmo dará respaldo aos técnicos quanto à motivação das inspeções.

e) Demandas encaminhadas pelo setor de epidemiologia em saúde do trabalhador ao setor de VAPT sem a devida investigação prévia.

[...] é necessário que tenha uma investigação prévia, para que não ocorra como uma vez que o endereço estava errado, ao invés do endereço da empresa, estava o endereço residência da pessoa que sofreu o acidente $[\ldots]$

[...] uma vez nos entregaram uma declaração de óbito pra fazer a investigação na empresa, quando fomos solicitar uma cópia da notificação do SINAN, esse caso não tinha sido notificado, nos encaminharam a D.O sem notificar, nos passaram o caso sem investigação da ficha [...]

Houve relatos de alguns casos que foram encaminhadas do setor de Vigilância Epidemiológica de Campo da Saúde do Trabalhador para a Vigilância em Ambiente e Processos de Trabalho sem que tivesse ocorrido uma prévia investigação da ficha, fato este que é de extrema importância e determinante para a devida preparação para a inspeção in loco. Para tanto foram realizadas sugestões de como deverá ocorrer o envio desse formulário:

[...] a medida que tomamos conhecimento da notificação, fazemos uma análise, verificamos a necessidade de uma inspeção e encaminhamos a solicitação, acho que já poderia ter uma pasta com esse formulário pronto [...] temos que anexar uma cópia da notificação, e já tem que ter tido a investigação da ficha. 
f) Deficiência no fluxo de encaminhamento dos casos de Acidente de Trabalho Grave entre os setores:

[...] outro assunto que a gente tem que falar é sobre fazer investigação de ATG, a gente fazia todos que aconteciam e hoje isso não está ocorrendo mais, a VAPT está recebendo apenas de alguns, eu acho que todo ATG típico deveria ser investigado [...]

A queixa da falta de investigação em alguns casos que eram rotineiros de inspeção surgiu nos relatos da equipe. Acredita-se que o fato se deve em parte pelas mudanças que ocorreram no setor nos últimos tempos, associado ao reduzido número de profissionais que estão disponíveis para atuar nessas vigilâncias.

\section{IV.Fluxos e instrumentos necessários para a estruturação do setor no planejamento e execução de suas ações}

Percebe-se que o fluxo existente foi criado a partir de experiências prévias adquiridas no decorrer dos anos, porém o mesmo não se encontra estruturado formalmente no momento atual. Além disso, se verifica que algumas questões estão dúbias entre os membros da equipe, alguns deles com várias dúvidas relativas a esta estrutura. Acredita-se que os processos de mudanças ocorridas nos anos de 2014 e 2016 podem ter contribuído para a ocorrência deste contexto. Verifica-se a emergente necessidade de nivelamento deste conhecimento entre os pares, bem como de construção de um fluxograma, a fim de estabelecer o mesmo na rotina da equipe.

Segue a nova proposta construída e validada pela equipe. Estas foram estruturadas no decorrer das fases metodológicas III e IV, momento em que, a partir do grupo focal, foram identificadas as necessidades de melhorias para a reestruturação e construção dos fluxos dos processos de trabalho, abaixo descritos:

\section{a) Elaboração de um fluxograma para entradas das solicitações de inspeção em ambientes e processos de trabalho:}

Segundo Oliveira ${ }^{21}$, "fluxograma é a representação gráfica que apresenta a sequência de um trabalho de forma analítica, caracterizando as operações, os responsáveis e/ou unidades organizacionais envolvidas no processo". Apresenta como objetivo evidenciar a sequência de trabalho, permitindo a visualização dos movimentos ilógicos ${ }^{22}$. Ou seja, fluxograma é uma técnica utilizada para representar graficamente as etapas de um processo, permitindo a visualização do fluxo e sua análise.

A nova estrutura do fluxograma de referência para as solicitações de Vigilância nos Ambientes e Processos de Trabalho, definida como produto resultante desta pesquisa, contará com a seguinte estrutura: 
Figura 01: Fluxograma de entrada

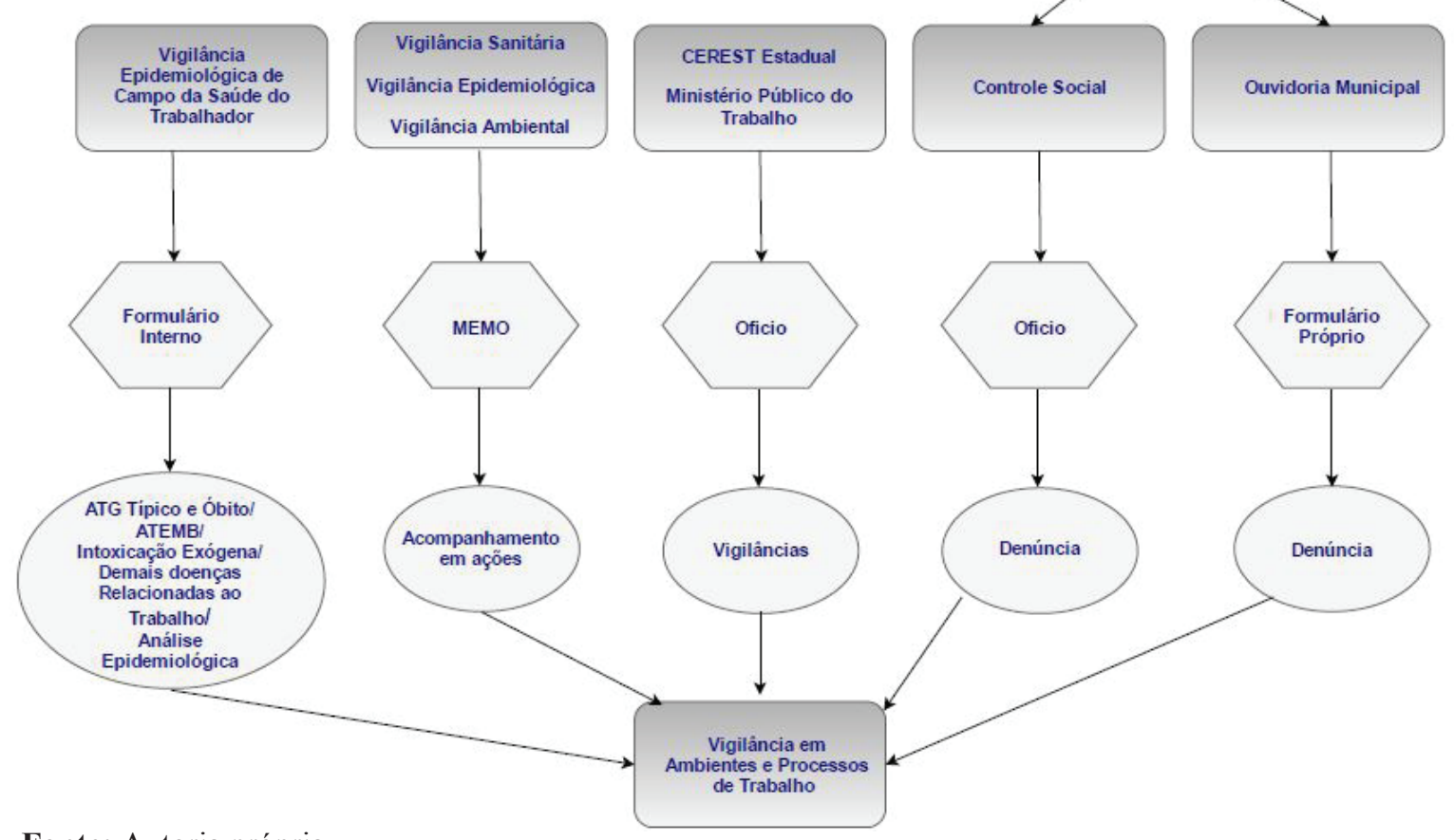

Fonte: Autoria própria.

As demanda internas de referência e contra-referência da Vigilância em Saúde do Trabalhador deverão ser encaminhadas através de formulário elaborado especificamente para esses casos, levando em consideração os critérios definidos, Acidente de Trabalho Grave (ATG) Típico e Fatal, Acidente com Exposição a Material Biológico (ATEMB), Intoxicação exógena, demais doenças relacionadas ao trabalho e solicitações decorrente de análise epidemiológica.

As demanda da Vigilância em Saúde (Sanitária, Epidemiológica, Ambiental), deverão ser encaminhadas via memorando. As oriundas de parceiros externos à SEMUS, como o Controle Social, CEREST estadual, Ministério Público e Ministério Público do Trabalho e Emprego, através de oficio. As demais solicitações, provenientes de denúncia, terão como porta de entrada a ouvidoria municipal, que deverá seguir seu próprio fluxo até a entrega no setor de VAPT.

As respostas às demandas solicitadas seguirão o mesmo fluxo de entrada.

Figura 02: Fluxograma de saída 


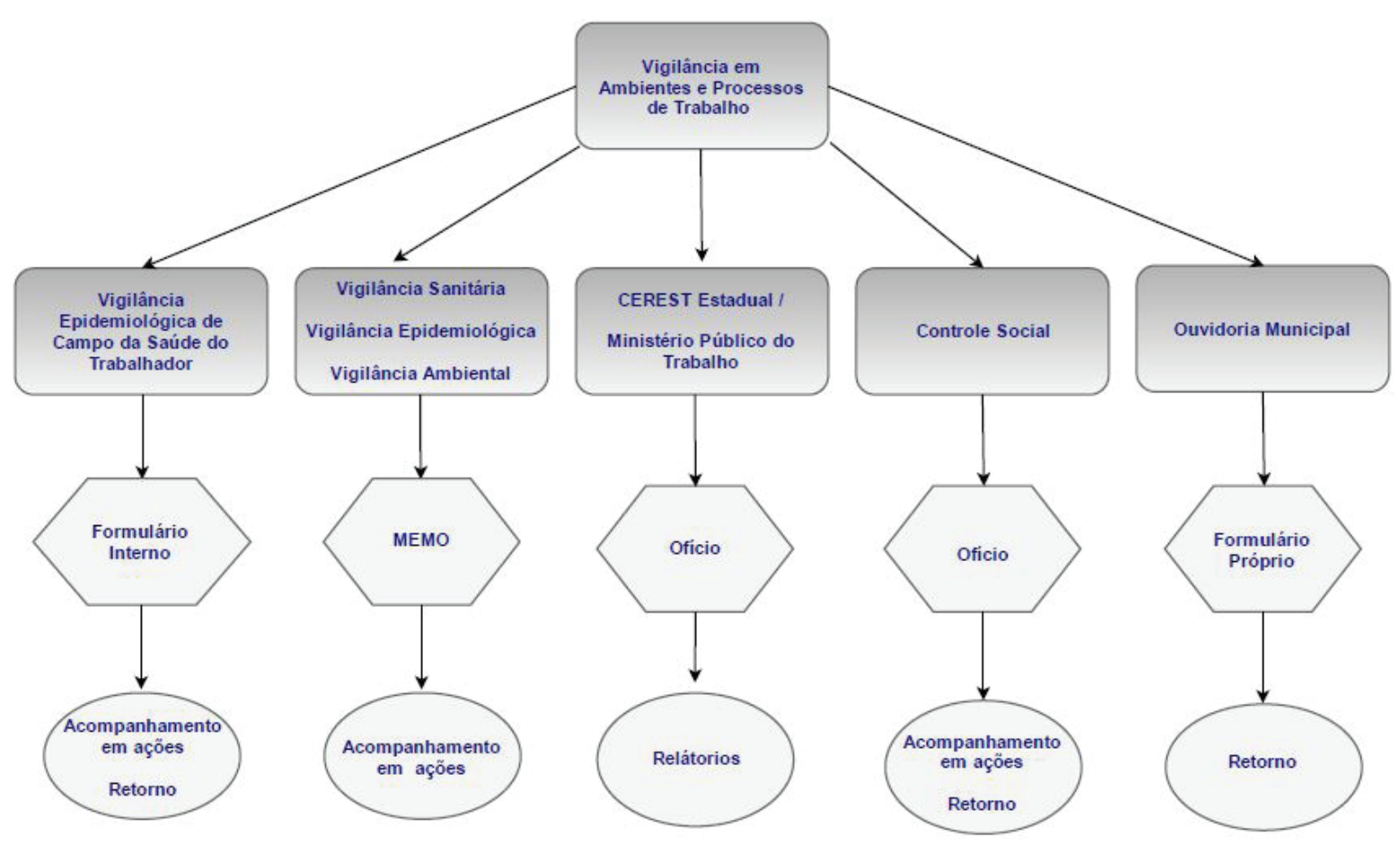

Elaboração de formulário para referência e contra-referência entre os setores da Vigilância em Saúde do Trabalhador:

Como resultado deste estudo, o mesmo foi construído a partir da análise do material resultante do grupo focal, que apontou as necessidades do setor pesquisado. Associou-se a este, conceitos teóricos acerca do assunto, com posterior validação pela equipe. Levou em consideração a realidade do setor e o objetivo de contemplar todos os aspectos relevantes de uma solicitação. Conta com campos de preenchimento obrigatório e se apresenta de modo autoexplicativo, tendo a finalidade de contemplar as especificidades da equipe, de formalização da referência e contrareferência. 
Figura 03: Formulário de Encaminhamento Interno.

FORMULÁRIO DE ENCAMINHAMENTO INTERNO DE SOLICTTAÇÕES DE INSPEÇÃO DO NÚCLEO EPIDEMIOLÓGICO PARA A VAPT

\begin{tabular}{|c|c|c|c|c|}
\hline \\
\hline & & & & $N^{2}$ \\
\hline ATG TÍPICO E FATAL & $\begin{array}{c}\text { ATEMB } \\
\square\end{array}$ & $\begin{array}{l}\text { INTOXICAÇÁO } \\
\text { EXÓGENA } \\
\square\end{array}$ & $\begin{array}{l}\text { OUTRAS DOENÇAS } \\
\text { RELACIONADAS AO TRABALHO }\end{array}$ & $\begin{array}{c}\text { ANÁLISE } \\
\text { EPIDEMIOLÓGICA }\end{array}$ \\
\hline \multicolumn{3}{|l|}{ NOME DO PACIENTE: } & \multicolumn{2}{|l|}{$\begin{array}{l}\text { No Notificação: } \\
\text { (anexar cópia da notificação) }\end{array}$} \\
\hline \multicolumn{3}{|l|}{ Ocupação: } & \multicolumn{2}{|l|}{ Data do Acidente: } \\
\hline \multicolumn{3}{|l|}{ Empresa: } & \multicolumn{2}{|l|}{ Ramo Produtivo } \\
\hline \multicolumn{5}{|l|}{ Endereço da Empresa: } \\
\hline \multicolumn{5}{|c|}{ Descrição Caso / Analise Epidemiológica: } \\
\hline \multicolumn{3}{|l|}{ Técnico Responsável: } & \multicolumn{2}{|c|}{ Território: } \\
\hline
\end{tabular}

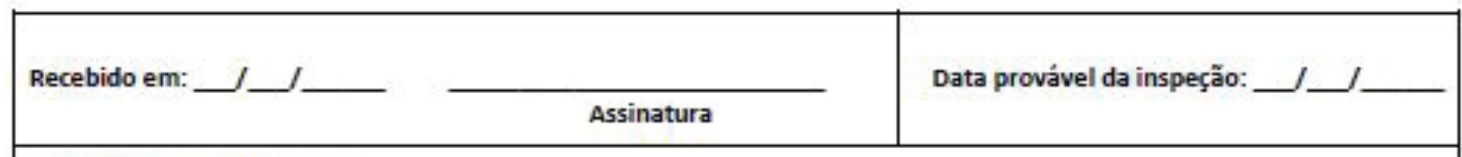

Parecer/Desfecho do caso:

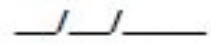

Fonte: Autoria Própria.

\section{b) Prazo para respostas as solicitações recebidas}

Foi definido que os prazos para resposta e realização das inspeções serão definidos pelo técnico da área que receber a solicitação, após verificação da demanda pendente no setor e recursos disponíveis para sua realização, como disponibilidade de pessoal e de veículo. O prazo poderá ser prorrogado com aviso prévio ao solicitante, sempre que necessário. 


\section{CONSIDERAÇÕES FINAIS}

O presente estudo possibilitou a realização de um diagnóstico situacional do setor de Vigilância nos Ambientes e Processos de Trabalho do Núcleo de Vigilância em Saúde do Trabalhador no município de Palmas - TO. A partir dele, evidenciou-se a importante missão que o mesmo tem a atribuição de desempenhar, bem como os percalços e as fragilidades enfrentadas no decorrer de sua história.

O processo de desabilitação do CEREST Regional de Palmas e criação do Núcleo de Vigilância em Saúde do Trabalhador, resultou em uma série de mudanças na organização deste serviço a nível municipal. Verificou-se que esse contexto facilitou a ampliação das ações, tendo em vista a redução do território de atuação da equipe. Em contrapartida, trouxe algumas fragilidades, como: ausência de recurso federal para o desenvolvimento do plano de trabalho e de uma legislação municipal que fortaleça a atuação da equipe técnica. Também apresentou a necessidade de realinhamento do novo modelo de atuação.

Percebe-se no cenário atual, que alguns dos desafios identificados são possíveis de resolução a partir de uma readequação de fluxos e instrumentos utilizados no processo de trabalho, proposta apresentada pelo grupo e construída nesta pesquisa de maneira participativa e democrática. Já outros dependem de intervenções dos gestores municipais, federais e do Conselho Municipal de Saúde.

Apesar das ações serem continuamente desenvolvidas pelo setor pesquisado, as questões apresentadas tornam essa execução desgastante, exigindo mais de seus técnicos no cumprimento do trabalho prescrito, desde o planejamento até sua realização. Cita-se como exemplo, a constante dependência de agenda de alguns setores e a dificuldade na implementação de novas estratégias de atuação em decorrência de um orçamento apertado.

Espera-se que esse trabalho contribua para sanar alguns itens elencados como dificuldade e que se tornaram visíveis a partir deste estudo, através da instituição efetiva e formal dos fluxos supramencionados e dos critérios para utilização dos mesmos. Importante salientar que esta contribuição só foi possível a partir de uma escuta qualificada do trabalhador, sendo este, o maior conhecedor do processo de trabalho a que está inserido, com suas fortalezas e fragilidades, fato que favoreceu uma intervenção adequada as reais necessidades da equipe.

Deseja-se ainda, que aqueles desafios que fogem do alcance de resolução desta pesquisa, possam servir de reflexão e análise para futuras intervenções dos gestores na realidade apresentada, que possivelmente, se repete em vários locais do país.

\section{REFERENCIAS}


sília, DF: Senado Federal; 1988.

2 Brasil. Lei n. 8.080, de 19 se setembro de 1990. Lei Orgânica da Saúde. Brasília, 1990.

3 Ministério da Saúde (Brasil). Portaria n. ${ }^{\circ} 3.120$, de $1^{\circ}$ de Julho de 1998. Aprova a Instrução Normativa de Vigilância em Saúde do Trabalhador no SUS, na forma do Anexo a esta Portaria, com a finalidade de definir procedimentos básicos para o desenvolvimento das ações correspondentes.

$4 \quad$ Ministério da Saúde (Brasil). Portaria GM no 1679 de 19 de setembro de 2002.

Dispõe sobre a estruturação da rede nacional de atenção integral à saúde do trabalhador no SUS e dá outras providências

Institui a Política Nacional de Saúde do Trabalhador e da Trabalhadora.

6 Laguardia FC, Quintino ND, Gusmão RB, Moraes CA, Oliveira PBB. Instrutivo para execução e avaliação das ações de vigilância em saúde: projeto fortalecimento da vigilância em saúde em Minas Gerais. 400p. Belo Horizonte, Autêntica Editora; 2014.

$7 \quad$ Ministério da Saúde (Brasil). Portaria No 2.437 de 7 de dezembro de 2005. Dispõe sobre a ampliação e o fortalecimento da Rede de Atenção Integral à Saúde do Trabalhador - RENAST, no Sistema Único de Saúde - SUS e dá outras providencias.

8 Ministério da Saúde (Brasil). Portaria No 2.728 de 11 de novembro de 2009. Dispõe sobre a Rede Nacional de Atenção Integral à Saúde do Trabalhador - RENAST e dá outras providâncias.

9 Franco, TB. Processos de trabalho e transição tecnológica na saúde: um olhar a partir do cartão nacional de saúde (tese). Faculdade de Medicina, Universidade Estadual de Campinas, Campinas; 2003a.

10 GERHARDT TE, SILVEIRA DT. Métodos de pesquisa. Porto Alegre: Editora UFRGS, 2009.

11 Iervolino AS, Pelicioni MCF. A utilização do grupo focal como metodologia qualitativa na promoção da saúde. Rev Esc Enf USP. 2001; 35(2):115-21.

12 Bardln L. Análise de conteúdo. Lisboa: Edições; 1977.

13 Chizzotti A. Parte II: Pesquisa Qualitativa. Pesquisa em Ciências Humanas e Sociais. São Paulo: Cortez, 2001. 
14 FRANCO TB. O uso do fluxograma descritor e projetos terapêuticos para análise de serviços de saúde, em apoio ao planejamento: o caso de luz (MG). O trabalho em saúde: olhando e experienciando o SUS no cotidiano. São Paulo: Hucitec, 2003 b.

15 Ministério da Saúde (Brasil). Portaria n ${ }^{\circ}$ 135, de 23 de abril de 2004. Habilita Centros de Referência em Saúde do Trabalhador para realizar os procedimentos previstos na Portaria GM/MS n 1.679, de 20 de setembro de 2002. Diário Oficial da União, de 26 de abril de 2004, seção 1.

16 Gomes EM, Santos MNC. A Construção da saúde do trabalhador na Rede SUS no Tocantins (monografia) - Fiocruz; 2008.

17 Oliveira Filho JF, Nascimento MDWR, Arantes RCC, Albuquerque SR. Diagnóstico situacional CEREST Regional de Palmas (monografia) - Fundação escola de Saúde Pública; 2011.

18 Conselho Municipal de Saúde (Brasil). RESOLUÇÃO No 14, de 23 de julho de 2014. Aprova a desabilitação do CEREST Regional de Palmas e a Habilitação do CEREST municipal de Palmas. Diário Oficial do município de Palmas-TO 17 de dezembro de 2014.

19 Secretaria municipal de Saúde (Brasil). Portaria Institucional No 518/SEMUS/ GAB, de 14 de junho de 2016. Institui a Rede de Atenção e Vigilância em Saúde (RAVS-PALMAS). Diário Oficial do município de Palmas-TO 28 de junho de 2016.

BRASIL. MINISTÉRIO DA SAÚDE. SECRETARIA DE ATENÇÃO À SAÚDE. DEPARTAMENTO DE ATENÇÃO BÁSICA. Política nacional de atenção básica. Ministério da Saúde, 2006.

21 Oliveira DPR. Sistemas, organização e métodos: uma abordagem gerencial. 15. ed. São Paulo: Atlas, 2005.

22 Araujo LCG. Organização, sistemas e métodos e as tecnologias de gestão organizacional: arquitetura organizacional, benchmarking, empowerment, gestão pela qualidade total, reengenharia. 3. ed. São Paulo: Atlas, 2007.

Artigo apresentado em 13/04/2017

Artigo aprovado em 27/02/2018 Artigo publicado no sistema em 05/03/2018 